Article

\title{
Projected Impacts of Climate Change on the Protected Areas of Myanmar
}

\author{
Thazin Nwe ${ }^{1,2}$, Robert J. Zomer ${ }^{3}(\mathbb{D})$ and Richard T. Corlett ${ }^{1,4, *(D)}$ \\ 1 Center for Integrative Conservation, Xishuangbanna Tropical Botanical Garden, Chinese Academy of \\ Sciences, Menglun 666303, China; thazin@xtbg.ac.cn \\ 2 University of Chinese Academy of Sciences, Beijing 100049, China \\ 3 Center for Mountain Futures, Kunming Institute of Botany, Chinese Academy of Sciences, \\ Kunming 650201, China; r.zomer@mac.com \\ 4 Center of Conservation Biology, Core Botanical Gardens, Chinese Academy of Sciences, \\ Menglun 666303, China \\ * Correspondence: corlett@xtbg.org.cn; Tel.: +86-182-8805-9408
}

Received: 29 July 2020; Accepted: 24 August 2020; Published: 25 August 2020

check for updates

\begin{abstract}
Protected areas are the backbone of biodiversity conservation but are fixed in space and vulnerable to anthropogenic climate change. Myanmar is exceptionally rich in biodiversity but has a small protected area system. This study aimed to assess the potential vulnerability of this system to climate change. In the absence of good biodiversity data, we used a spatial modeling approach based on a statistically derived bioclimatic stratification (the Global Environmental Stratification, GEnS) to understand the spatial implications of projected climate change for Myanmar's protected area system by 2050 and 2070. Nine bioclimatic zones and 41 strata were recognized in Myanmar, but their representation in the protected area system varied greatly, with the driest zones especially underrepresented. Under climate change, most zones will shift upslope, with some protected areas projected to change entirely to a new bioclimate. Potential impacts on biodiversity include mountaintop extinctions of species endemic to isolated peaks, loss of climate specialists from small protected areas and those with little elevational range, and woody encroachment into savannas and open forests as a result of both climate change and rising atmospheric $\mathrm{CO}_{2}$. Myanmar needs larger, better connected, and more representative protected areas, but political, social, and economic problems make this difficult.
\end{abstract}

Keywords: bioclimates; biodiversity; climate change; climate types; conservation planning; Global Environmental Stratification; tropical Asia; tropical forests; Southeast Asia

\section{Introduction}

\subsection{Climate Change and Protected Areas}

Tropical East Asia supports 15-25\% of global terrestrial biodiversity in around 4\% of Earth's total land area [1], but is also one of the most threatened regions of the planet [2]. Major threats include the world's highest deforestation rates [3], widespread habitat degradation [4], hunting [5], wildlife consumption and trade [6], and unsustainable land use [7]. In the near future, climate change is likely to become an additional major driver of habitat degradation and species loss [8]. Warming in the tropics has been large relative to natural climate variability, so most regions are already experiencing thermal climates that were unknown in the 19th century [9]. In contrast, changes in precipitation in tropical East Asia have generally been small relative to natural variability. In other parts of the world, many species are already shifting their distributions towards higher altitudes and latitudes [10], but there have been few observations of this in tropical Asia [1,8]. 
Protected areas (PAs) are the backbone of global biodiversity conservation, but they are fixed in space and the species they protect can respond to climate change only by acclimation and adaptation in situ, by movements within them, or by dispersing to other areas in the regional PA network [11]. Moreover, the ability to disperse to new areas does not ensure survival, although these range shifts may increase the prospect of persistence for some species and populations. There are barriers to movement such as human activities and species interactions [12], and unsuitable geological substrates [13]. Even where there are no barriers, many species may not be able to track high local velocities of climate change $[14,15]$.

The effectiveness of existing PAs in mitigating the impacts of climate change has been questioned, because of their immobility, spatial bias, and low percentage coverage [16]. Species will be lost from existing PAs if their entire climate envelope shifts outside the boundaries. However, there is empirical evidence that protected areas and networks can help to protect biodiversity in the face of both climate change and habitat loss [10]. These studies also suggest ways in which protected area networks can be modified to reduce their vulnerability. A recent study showed that an optimum configuration of protection for $30 \%$ of tropical land area, combined with limiting global warming to $<2{ }^{\circ} \mathrm{C}$, reduces tropical extinction risks by more than $50 \%$ [17].

\subsection{Myanmar}

Myanmar is the second largest country in Southeast Asia, with a land area of $676,577 \mathrm{~km}^{2}$ and human population of 54 million. It extends from $9^{\circ} 28^{\prime}$ to $28^{\circ} 29^{\prime} \mathrm{N}$ and $92^{\circ} 10^{\prime}$ to $101^{\circ} 10^{\prime} \mathrm{E}$, bordering India, Bangladesh, the Bay of Bengal, and the Andaman Sea in the west, and China, Laos, and Thailand in the east. Geographically, it is exceptionally diverse, with coastal plains, the central basin and lowlands, the western ranges, the eastern Shan plateau, and mountains in the north, rising to $5881 \mathrm{~m}$ at Hkakabo Razi. The climate is dominated by the southwest monsoon, which interacts with the topography to produce a wide range of different climate types. In most areas there are three distinct seasons: a cooler winter season from early November to late February, a hot season from March to mid-May, and a rainy season from mid-May to mid-October. Mean annual rainfall is $500-1000 \mathrm{~mm}$ in the central dry zone, higher in the eastern and northern mountains, and highest in the southern and Rakhine coastal regions, where it can exceed $5000 \mathrm{~mm}$. Mean annual temperature declines with altitude, from $26-28{ }^{\circ} \mathrm{C}$ in the tropical lowlands to $<0{ }^{\circ} \mathrm{C}$ on the summits of the highest mountains, and temperature seasonality increases with latitude, with little variation in the south [18].

Myanmar is recognized as one of the most biodiverse countries in the world, as a result of the interaction between geography, topography, and climatic conditions [19]. It forms a major part of the Indo-Burma biodiversity hotspot, which is a global priority for conservation, with high levels of diversity and endemism, but also increasing threats from habitat loss and overexploitation [2]. Myanmar contains a great diversity of ecosystems, but most of the land area would have supported dense forests of some kind, except for areas above the treeline at c. $4000 \mathrm{~m}$ in the far north, and the drier parts of the central dry zone, which were covered in open forest and savanna. Dense forests ranged from lowland tropical rainforest in the south to evergreen needle-leaf forests above $3000 \mathrm{~m}$ in the far north. Much of this forest has been cleared or badly degraded. Forest still covered $44 \%$ of the land area in 2020, but the annual rate of forest loss for 2010-2020 was 1\%, which was the second highest percentage loss in Southeast Asia and the 7th highest in the world for net forest area loss [20]. Deforestation rates were even higher in mangrove forest (3.60-3.87\% for 1996-2016) [21].

Due to the economic and political isolation of Myanmar over the past 70 years, as well as internal conflicts in some regions, it retains a higher amount of native forest and the largest areas of unfragmented forest ecosystems in the region [22]. However, Myanmar is one of the least developed countries in Asia and, along with the rapid socio-economic development, it is facing accelerating deforestation under a more open and democratic political system [23,24]. The transformation of land use from subsistence to commercial agricultural production has accelerated since the late 1980s: oil palm 
concessions in southern Myanmar and rubber plantations in south-eastern Myanmar (Tanintharyi Division, Mon State, and Kayin State) have had significant impacts on biodiversity [23,25].

Existing threats to biodiversity in Myanmar can be made more serious by climate change, through both direct impacts, like the loss of suitable habitat for species and reduced resilience in ecosystems, and through indirect impacts on humans and their dependence on the products and services produced by natural ecosystems [26]. Climate change impacts on biodiversity in Myanmar are still understudied, however. Between 1981 and 2010, the mean annual temperature increased by $0.25^{\circ} \mathrm{C}$ per decade, within inland regions warming faster than coastal regions, and the mean annual rainfall also increased in most regions [18]. According to the Global Climate Risk Index 2020, Myanmar was the country second most affected by extreme weather events between 1999 and 2018, although 95\% of the damage and casualties were caused by a single event, Cyclone Nargis, in 2008 [27]. The number of drought and flood events has increased, as has the intensity and frequency of cyclones. Cyclones Mala (2006), Nargis (2008), and Giri (2010) were the most severe and damaging cyclones Myanmar has experienced. Moreover, during the summer of 2010, 1482 cases of heat-related disorders and 260 heat-related deaths due to extreme high temperature were reported, and in July and August 2015, 1.6 million people were displaced as the result of flooding and landslides [28].

\subsection{Myanmar's Protected Area System}

Myanmar's first protected areas were established as wildlife sanctuaries around Buddhist monasteries since the 11th Century and some of these were transformed into formal protected areas to protect endangered wildlife species during the colonial period [29]. However, the major expansion in the number of PAs and the total area protected has occurred since 1980. There are currently 45 protected areas, covering $5.85 \%$ of the country's area, under the management of the Nature and Wildlife Conservation Division (NWCD) within the Ministry of Natural Resources and Environmental Conservation [30]. Among the 45 current PAs, eight (Hkakaborazi National Park, Htamanthi Wildlife Sanctuary, Indawgyi Lake Wildlife Sanctuary, Alaungdaw Kathapa National Park, Inlay Lake Wildlife Sanctuary, Meinmahla Kyun Wildlife Sanctuary, Lampi Marine National Park, and Natmataung National Park) have been recognized as ASEAN Heritage Parks (AHPs) for their particular biodiversity value or uniqueness within ASEAN countries [30].

The PA system is intended to represent the full complement of the country's biogeographic regions, but in practice, their effectiveness in conserving biodiversity is reduced by additional factors related to size, geographic representation, inadequate funding and management capacity, weak policy, and the regulatory framework [26]. Some PAs are close to national borders, like Khakaborazi National Park, Lenya National Park (with Namtok Huay Yang in Thailand), Tanintharyi Nature Reserve (with Kaengkrachan Forest Complex in Thailand), but still lack transboundary protected area management, which can play a crucial role in preserving biodiversity. Three of the 45 protected areas (Htaung Wi Taung, Thamihla Kyun Wildlife Sanctuary, and Eaisarthaya Cave-Geographic-Features Significant Area Myanmar) were omitted from the analyses in this study because they are very small.

Optimization of the spatial configuration of protected area networks would ideally be based on species distribution data [17], but such data are often missing, very patchy, or inaccessible in Myanmar. In this paper, therefore, we used a spatial modeling approach based on a statistically derived bioclimatic stratification $[31,32]$ to understand the spatial implications of projected climate change for Myanmar's protected area network by 2050 and 2070. Changes in the distribution of bioclimatic zones and strata are used as indicators of potential impacts on species and ecosystems. This approach avoids the "cascade of model uncertainties" associated with the modeling of biological impacts, even in areas where the species distribution data are available [32]. The main objectives were:

1. To summarize the temporal and spatial patterns of climate change projected for Myanmar by 2050 and 2070.

2. To classify and map the climate types currently present in Myanmar and project the changes in the areas and spatial distributions of these climate types by 2050 and 2070. 
3. To assess the representativeness of the protected area system in terms of the current climate types present in Myanmar.

4. To assess the impact of projected climate change on the representation of climate types within individual protected areas and in the protected area system as a whole.

5. To identify the likely impacts of climate change on the protection of biodiversity in Myanmar's protected areas.

\section{Materials and Methods}

\subsection{Bioclimatic Stratification}

A spatial modeling approach based on a statistically derived bioclimatic stratification was used to predict and understand the spatial implications of projected climate conditions for Myanmar by the year 2050 and 2070. The spatial shifts of bioclimatic zones and strata were evaluated to estimate the potential impacts of climate change across Myanmar. The construction of the Global Environmental Stratification (GEnS), used here, is described in detail by Metzger et al. [33] and its use in the interpretation, understanding, and communication of global climate change projections is discussed by [32]. The GEnS is intended to be a globally consistent classification of land into relatively homogenous units, based on a statistical clustering of climate variables [33]. The GEnS classifies the world's land surface into 125 relatively homogeneous bioclimatic strata, aggregated into 18 zones, based upon a statistical analysis of current climate data (1961-2000). The zones have descriptive names while the strata have unique codes. To produce the original GEnS, Metzger et al. identified a subset of 36 biophysically relevant bioclimatic variables based on a statistical screening of 42 variables available from various climate datasets [33]. Principal Components Analysis revealed that the first three principal components, explaining greater than $99 \%$ of the total variation, were determined by only four variables.

$>$ Degree days $>0{ }^{\circ} \mathrm{C}[34]$

- Daily sum of annual degrees of temperature above $0{ }^{\circ} \mathrm{C}$, reflecting latitudinal and altitudinal temperature gradients, and plant growth periods [34].

$>$ Aridity-Wetness Index (AWI) [35]

- Ratio of annual precipitation over annual potential evapotranspiration (PET), calculated globally using the Hargreaves (1994) model [36].

$>$ Monthly mean temperature seasonality [34]

- Standard deviation of the monthly mean temperature distribution

$>$ Potential evapotranspiration (PET) seasonality [35]

- Standard deviation of the monthly mean PET distribution.

\subsection{Modeling of Projected Future Climate Conditions}

Projected future conditions for the years 2050 (average for 2041-2060) and 2070 (average for 2061-2080), also derived from WorldClim 1.4, were selected to represent a short to medium-term time frame relevant to the needs of ecosystem managers, planners, and other policy and decision makers. The environmental stratification of Myanmar, which is based on climate data from 1960 to 2000, was reconstructed for 2050 and 2070, based upon projections for future climate conditions from three CMIP5 Earth System Models (ESMs), HadGEM2-ES, CNRM-CM5 and GFDL-CM3, which have been previously recommended for the region [37,38]. We used two Representative Concentration Pathways (RCPs), RCP2.6 and RCP8.5, representing the low and high greenhouse gas concentration 
scenarios, respectively [39]. The socio-economic assumptions on which these scenarios were originally based are no longer realistic in 2020, but they still serve to bracket the potential range of radiative forcing by the end of the century. RCP2.6 is consistent with meeting the Paris Agreement's $2{ }^{\circ} \mathrm{C}$ global warming target. The ESM runs were downscaled using the Delta method to $1 \mathrm{~km}^{2}$ resolution, as with the current climate conditions. Note that the stratification is based on the current climate and that future climates are assigned to the most similar current climate zone and stratum.

\section{Results}

\subsection{Projected Climate Change by 2050 and 2070}

The mean annual temperature for Myanmar in $1960-2000$ was $23.2^{\circ} \mathrm{C}$, mean maximum temperature of the warmest month was $32.9^{\circ} \mathrm{C}$, and mean annual precipitation was $1992.4 \mathrm{~mm}$. The CMIP5 model projections for Myanmar in 2050 and 2070 show an acceleration of recent warming trends. By 2050 , mean annual temperature is predicted to increase by $1.1-2.0^{\circ} \mathrm{C}$ under RCP2.6 and $1.7-3.0^{\circ} \mathrm{C}$ under RCP8.5 (Supplementary Material Table S1). The projected increase in mean annual temperature by 2050 is greatest in the eastern parts of Myanmar, approaching and exceeding $3.0^{\circ} \mathrm{C}$ under the RCP8.5 scenario with GFDL-CM3 and HadGEM2-ES (Supplementary Material Figure S1). By 2070, mean annual temperature is predicted to increase by $1.2-2.3^{\circ} \mathrm{C}$ under RCP2.6 and $2.6-4.4{ }^{\circ} \mathrm{C}$ under RCP8.5 (Supplementary Material Table S1). The increase in mean annual temperature by 2070 is high across almost all of Myanmar, approaching and exceeding $4.0^{\circ} \mathrm{C}$ under the RCP8.5 scenario with GFDL-CM3 and HadGEM2-ES (Supplementary Material Figure S2). Mean maximum temperature is predicted to increase by $1.1-1.8^{\circ} \mathrm{C}$ under RCP2.6 and $1.4-3.1^{\circ} \mathrm{C}$ under RCP8.5 by 2050 and $1.0-1.8^{\circ} \mathrm{C}$ under RCP2.6 and $2.4-4.0^{\circ} \mathrm{C}$ under RCP8.5 by 2070 (Supplementary Material Table S1) (Supplementary Material Figures S3 and S4).

In contrast to the generally consistent pattern of warming, there is a wider spread among models for projections of mean annual precipitation (Supplementary Material Table S1). By 2050, annual precipitation is predicted to increase by $1.6-5.4 \%(33-114 \mathrm{~mm})$ under RCP2.6 and change by $-1.5-6.2 \%$ (-30-133 mm) under RCP8.5 (Supplementary Material Table S1) (Supplementary Material Figure S5). By 2070, it is predicted to increase by $2.4-6.4 \%(49-137 \mathrm{~mm})$ under RCP2.6 and 5.2-8.5\% (109-184 mm) under RCP8.5 (Supplementary Material Figure S6). Note that these changes are small relative to current interannual variation, and to rainfall variability over the last 200 years reconstructed from a tree-ring chronology [40].

\subsection{Bioclimatic Stratification of Myanmar under Current Conditions}

Nine bioclimatic zones (Table 1) and 41 bioclimatic strata (Table 2) were identified in Myanmar (Figure 1), ranging from the Extremely Cold and Wet zone at the highest elevations in the north, with a single stratum, to the Extremely Hot and Xeric zone at low elevations in the central dry zone, with three strata, of which Q4 is the hottest and driest (Table 1). The mean annual temperatures for these zones are correlated with their average elevation and range from $-4.1^{\circ} \mathrm{C}$, for the coldest zone at an average elevation of $5409 \mathrm{~m}$ to $26.7^{\circ} \mathrm{C}$, for the hottest zone at an average elevation of $155 \mathrm{~m}$. The maximum temperatures are also correlated with their average elevation and range from $7.0^{\circ} \mathrm{C}$ for the coolest zone to $38.1{ }^{\circ} \mathrm{C}$ for the hottest zone. However, annual precipitation shows no consistent relationship with elevation. Of the nine zones, the three at the highest elevations (Extremely Cold and Wet, Extremely Cold and Mesic, and Cold and Mesic) each cover $<1 \%$ of the total land area of Myanmar. The zones with the largest areas are Extremely Hot and Moist, covering 224,377 $\mathrm{km}^{2}$ ( $34 \%$ of the total area), mostly in the south, and Hot and Mesic, covering $219,324 \mathrm{~km}^{2}(33 \%)$, mostly further north. 
Table 1. Characteristics of the bioclimatic zones in Myanmar based on climate data from 1960 to 2000.

\begin{tabular}{|c|c|c|c|c|c|c|}
\hline Bioclimatic Zone & Area $\left(\mathbf{k m}^{2}\right)$ & Area $(\%)$ & Mean Elevation (M A.S.L) & $\begin{array}{r}\text { Mean Annual } \\
\text { Temperature }\left({ }^{\circ} \mathrm{C}\right)\end{array}$ & $\begin{array}{l}\text { Mean Maximum } \\
\text { Temperature }\left({ }^{\circ} \mathrm{C}\right)\end{array}$ & $\begin{array}{r}\text { Mean Annual } \\
\text { Precipitation }(\mathrm{mm})\end{array}$ \\
\hline Extremely Cold and Wet & 3 & 0 & 5409 & -4.1 & 7.0 & 692.3 \\
\hline Extremely Cold and Mesic & 816 & 0 & 4450 & 1.2 & 12.4 & 749.9 \\
\hline Cold and Mesic & 2900 & 0 & 3612 & 5.9 & 16.3 & 969.2 \\
\hline Cool Temperate and Moist & 4831 & 1 & 2842 & 10.3 & 19.6 & 1362.7 \\
\hline Warm Temperate and Mesic & 55,576 & 8 & 1595 & 16.6 & 25.2 & 2219.7 \\
\hline Hot and Mesic & 219,324 & 33 & 579 & 22.7 & 32.2 & 2015.7 \\
\hline Hot and Dry & 78,900 & 12 & 1190 & 19.8 & 29.6 & 1551.2 \\
\hline Extremely Hot and Moist & 224,377 & 34 & 183 & 26.0 & 35.4 & 2449.8 \\
\hline Extremely Hot and Xeric & 77,215 & 12 & 155 & 26.7 & 38.1 & 949.7 \\
\hline
\end{tabular}

Table 2. Characteristics of the bioclimatic strata in Myanmar based on climate data from 1960 to 2000.

\begin{tabular}{|c|c|c|c|c|c|c|}
\hline Zone & Strata & $\begin{array}{r}\text { Area } \\
\left(\mathrm{km}^{2}\right)\end{array}$ & Mean Elevation (m) & $\begin{array}{r}\text { Mean Annual } \\
\text { Temperature }\left({ }^{\circ} \mathrm{C}\right)\end{array}$ & $\begin{array}{l}\text { Mean Maximum } \\
\text { Temperature }\left({ }^{\circ} \mathrm{C}\right)\end{array}$ & $\begin{array}{r}\text { Mean Annual } \\
\text { Precipitation }(\mathrm{mm})\end{array}$ \\
\hline D. Extremely cold and wet & D3 & 3 & 5409 & -4.1 & 7.0 & 692.3 \\
\hline \multirow{2}{*}{ F. Extremely cold and mesic } & $\mathrm{F} 4$ & 23 & 4940 & -1.9 & 9.3 & 700.6 \\
\hline & F13 & 793 & 4436 & 1.3 & 12.5 & 750.6 \\
\hline \multirow{2}{*}{ G. Cold and mesic } & G11 & 1649 & 3815 & 4.7 & 15.3 & 889.6 \\
\hline & G13 & 1251 & 3343 & 7.5 & 17.5 & 1074.2 \\
\hline \multirow{4}{*}{ J. Cool temperate and moist } & $\mathrm{J} 1$ & 245 & 3137 & 8.7 & 17.6 & 1379.4 \\
\hline & $\mathrm{J} 3$ & 1185 & 3026 & 9.2 & 18.9 & 1185.9 \\
\hline & $\mathrm{J} 4$ & 3291 & 2753 & 10.8 & 20.0 & 1422.6 \\
\hline & $\mathrm{J} 5$ & 89 & 2900 & 10.2 & 20.3 & 1152.4 \\
\hline \multirow{5}{*}{$\begin{array}{l}\text { K. Warm temperate } \\
\text { and mesic }\end{array}$} & K1 & 1139 & 2551 & 12.1 & 21.4 & 1380.4 \\
\hline & $\mathrm{K} 2$ & 5943 & 2236 & 13.4 & 22.0 & 1963.6 \\
\hline & K7 & 8341 & 1981 & 14.9 & 23.6 & 1767.9 \\
\hline & K10 & 5 & 2028 & 15.4 & 24.8 & 1381.4 \\
\hline & K12 & 33,429 & 1347 & 17.7 & 26.1 & 2534.1 \\
\hline
\end{tabular}


Table 2. Cont

\begin{tabular}{|c|c|c|c|c|c|c|}
\hline Zone & Strata & $\begin{array}{r}\text { Area } \\
\left(\mathrm{km}^{2}\right)\end{array}$ & Mean Elevation (m) & $\begin{array}{r}\text { Mean Annual } \\
\text { Temperature }\left({ }^{\circ} \mathrm{C}\right)\end{array}$ & $\begin{array}{l}\text { Mean Maximum } \\
\text { Temperature }\left({ }^{\circ} \mathrm{C}\right)\end{array}$ & $\begin{array}{r}\text { Mean Annual } \\
\text { Precipitation }(\mathrm{mm})\end{array}$ \\
\hline \multirow{7}{*}{ M. Hot and mesic } & M1 & 25,597 & 783 & 20.8 & 29.1 & 2680.0 \\
\hline & M2 & 48,533 & 784 & 21.7 & 31.6 & 1608.4 \\
\hline & M4 & 23,284 & 921 & 22.1 & 32.6 & 1315.9 \\
\hline & M5 & 25,050 & 294 & 23.7 & 31.8 & 3328.4 \\
\hline & M6 & 1 & 892 & 22.8 & 33.6 & 967.0 \\
\hline & M7 & 23,629 & 702 & 23.2 & 33.6 & 1351.2 \\
\hline & M8 & 73,230 & 320 & 23.8 & 33.2 & 2041.4 \\
\hline \multirow{5}{*}{ N. Hot and dry } & N3 & 24,895 & 1356 & 18.7 & 28.3 & 1611.0 \\
\hline & $\mathrm{N} 4$ & 27 & 1725 & 18.4 & 28.7 & 1213.5 \\
\hline & N8 & 36,707 & 1060 & 20.1 & 29.9 & 1616.5 \\
\hline & N9 & 7264 & 1332 & 19.9 & 30.1 & 1339.9 \\
\hline & N11 & 10,007 & 1145 & 20.9 & 31.3 & 1316.4 \\
\hline \multirow{10}{*}{ R. Extremely hot and moist } & R1 & 20,886 & 533 & 24.1 & 34.5 & 1400.4 \\
\hline & $\mathrm{R} 2$ & 331 & 783 & 24.3 & 35.7 & 968.3 \\
\hline & R3 & 17,682 & 226 & 25.5 & 33.8 & 3076.9 \\
\hline & $\mathrm{R} 4$ & 3400 & 397 & 25.1 & 32.3 & 1715.3 \\
\hline & R5 & 44,993 & 271 & 25.1 & 35.7 & 1233.9 \\
\hline & R6 & 11,244 & 270 & 25.7 & 34.5 & 2268.1 \\
\hline & R7 & 101,364 & 39 & 26.7 & 35.9 & 3276.1 \\
\hline & $\mathrm{R} 8$ & 5924 & 70 & 26.5 & 33.2 & 2940.5 \\
\hline & $\mathrm{R} 9$ & 17,097 & 272 & 26.1 & 37.0 & 1536.6 \\
\hline & R10 & 1456 & 67 & 26.6 & 33.2 & 2246.3 \\
\hline \multirow{3}{*}{ Q. Extremely hot and xeric } & Q1 & 45,901 & 188 & 26.5 & 37.8 & 832.8 \\
\hline & Q3 & 23,609 & 110 & 27.0 & 38.4 & 1244.2 \\
\hline & $\widehat{\mathrm{Q}} 4$ & 7705 & 93 & 27.4 & 39.1 & 744.3 \\
\hline
\end{tabular}




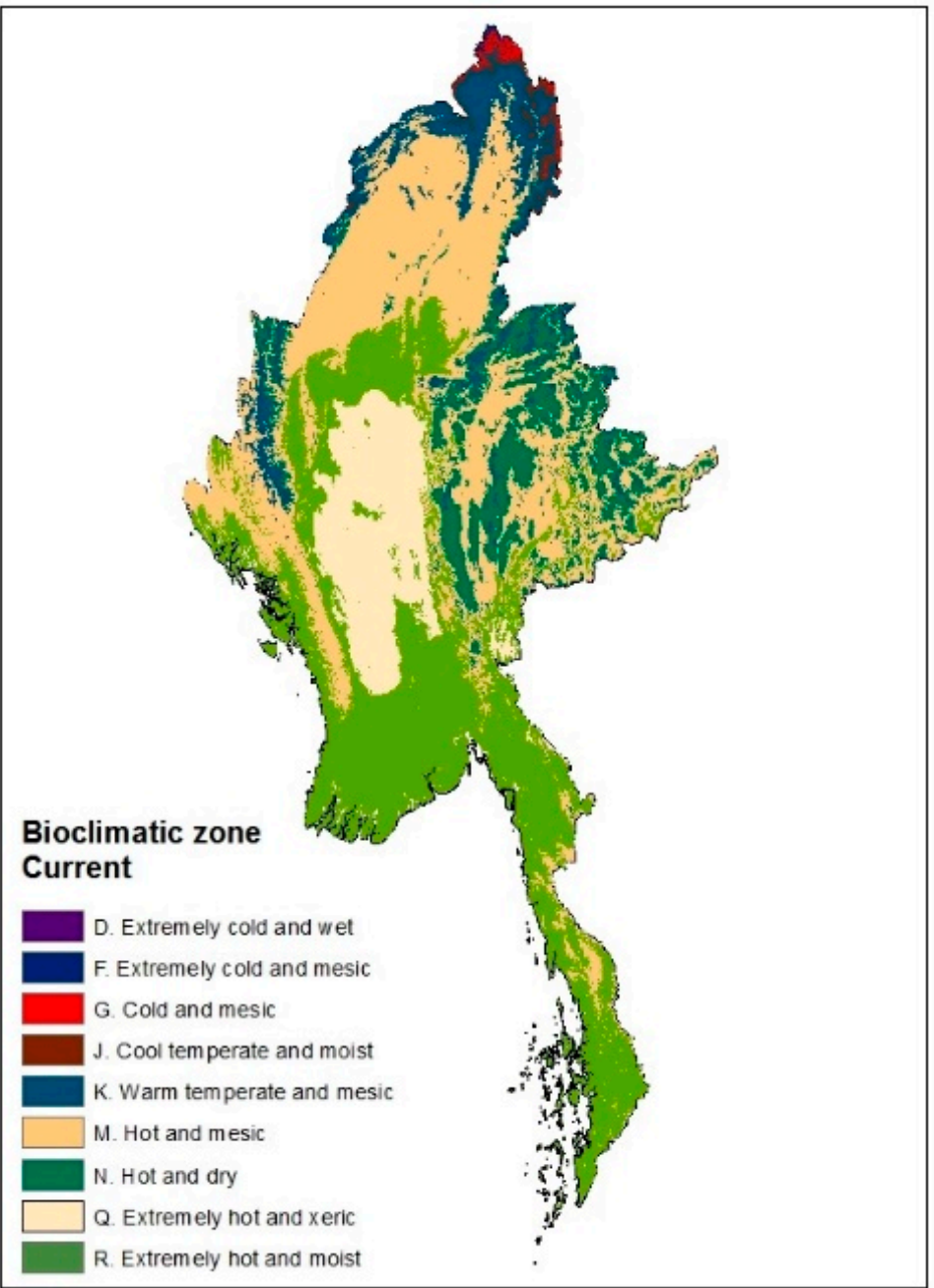

Figure 1. Distribution of the bioclimatic zones of Myanmar based on climate data from 1960-2000.

\subsection{Projected Changes in the Spatial Distribution of Bioclimatic Zones and Strata by 2050 and 2070}

By the year 2050, substantial spatial displacement of the bioclimatic zones is seen under both RCPs (Supplementary Material Figure S7). Under RCP2.6, there is a large expansion in the extents of the Extremely Hot and Xeric zone (from 77,215 $\mathrm{km}^{2}$ to 93,411-137,028 $\mathrm{km}^{2}$ ) and Extremely Hot and Moist zone (from 224,377 km² to 245,484-267,000 km²), and also in the Hot and Mesic zone (from 219,324 km² to $223,454-233,226 \mathrm{~km}^{2}$ ), except with HadGEM2-ES, which predicts a small decrease (from $219,324 \mathrm{~km}^{2}$ to $218,834 \mathrm{~km}^{2}$ ), while all other zones decrease with all models (Supplementary Material Table S2). All zones exhibit upward shifts in average elevation of 125-282 m. Under RCP8.5, there are similar expansions in the Extremely Hot and Xeric zone (from $77,215 \mathrm{~km}^{2}$ to $109,293-154,055 \mathrm{~km}^{2}$ ) and the Extremely Hot and Moist zone (from 224,377 $\mathrm{km}^{2}$ to $245,484-267,000 \mathrm{~km}^{2}$ ), but the Hot and Mesic zone expands only in CNRM-CM5 (from $219,324 \mathrm{~km}^{2}$ to $227,878 \mathrm{~km}^{2}$ ), while it decreases in GFDL-CM3 and HadGEM2-ES $\left(219,324 \mathrm{~km}^{2}\right.$ to $\left.184,533-172,060 \mathrm{~km}^{2}\right)$. The upward shift for all zones is 181-425 m. There are large decreases in the Hot and Dry zone under both RCP2.6 (from 78,900 $\mathrm{km}^{2}$ to 23,162-38,695 km²) and RCP8.5 (to 10,550-25,465 km²). (Supplementary Material Table S2). Changes in strata are larger than those for zones, reflecting their narrower definitions, but are model-dependent (Supplementary Material Table S4). Four new strata appear by 2050, but most only with GFDL-CM3, and several disappear. Overall, 9-13\% of the total area of Myanmar will change zone under RCP2.6 and $11-23 \%$ under RCP8.5, while $21-33 \%$ under RCP2.6 and 27-39\% under RCP8.5 will change stratum (Supplementary Material Table S3). 
In general, projected changes by 2070 are in the same direction as 2050, but larger for both zones and strata (Supplementary Material Figure S8). Under RCP2.6, there is a large expansion in the extent of the Extremely Hot and Xeric zone (from $77,215 \mathrm{~km}^{2}$ to $104,605-146,458 \mathrm{~km}^{2}$ ) and the Extremely Hot and Moist zone (from 224,377 km² to 242,222-264,775 km²) while the areal extent of all other zones decreases (Supplementary Material Table S3). All zones show an upward shift in average elevation of 128-309 m. Under RCP8.5, there are similar expansions in the Extremely Hot and Xeric zone (from 77,215 $\mathrm{km}^{2}$ to $84,563-137,241 \mathrm{~km}^{2}$ ) and the Extremely Hot and Moist zone (from $224,377 \mathrm{~km}^{2}$ to $278,832-426,970 \mathrm{~km}^{2}$ ), while all other zones decrease. The upward shift for all zones is 299-614 m. Interestingly, the Hot and Mesic zone will increase under RCP2.6 (from 219,324 km² to 222,830-224,671 km²), but decrease under RCP8.5 (from 219,324 km² to 127,610-199,490 km²) (Supplementary Material Table S4). Changes in strata are similar to but larger than those by 2050 (Supplementary Material Table S5). Overall, 8-14\% of the total area of Myanmar will change zone under RCP2.6 and 17-32\% under RCP8.5, while 20-35\% under RCP2.6 and 34-52\% under RCP8.5 will change stratum (Table 3).

Table 3. Land area and percentage of total land area in Myanmar that is projected to change its bioclimatic zone or stratum by 2050 and 2070, with three earth system models and two RCPs.

\begin{tabular}{|c|c|c|c|c|c|c|c|c|}
\hline \multirow{3}{*}{ Model } & \multicolumn{4}{|c|}{2050} & \multicolumn{4}{|c|}{2070} \\
\hline & \multicolumn{2}{|c|}{ Zone Shift $\mathrm{km}^{2}$} & \multicolumn{2}{|c|}{ Zone Shift \% } & \multicolumn{2}{|c|}{ Zone Shift km² } & \multicolumn{2}{|c|}{ Zone Shift \% } \\
\hline & RCP 2.6 & RCP 8.5 & RCP 2.6 & RCP 8.5 & RCP 2.6 & RCP 8.5 & RCP 2.6 & RCP 8.5 \\
\hline CNRM-CM5 & 56,453 & 74,424 & 9 & 11 & 54,881 & 114,481 & 8 & 17 \\
\hline GFDL-CM3 & 85,050 & 152,731 & 13 & 23 & 91,766 & 189,990 & 14 & 29 \\
\hline HadGEM3-ES & 77,305 & 137,663 & 12 & 21 & 76,846 & 209,941 & 12 & 32 \\
\hline \multirow{3}{*}{ Model } & \multicolumn{4}{|c|}{2050} & \multicolumn{4}{|c|}{2070} \\
\hline & \multicolumn{2}{|c|}{ Strata Shift km² } & \multicolumn{2}{|c|}{ Strata Shift \% } & \multicolumn{2}{|c|}{ Strata Shift $\mathrm{km}^{2}$} & \multicolumn{2}{|c|}{ Strata Shift \% } \\
\hline & RCP 2.6 & RCP 8.5 & RCP 2.6 & RCP 8.5 & RCP 2.6 & RCP 8.5 & RCP 2.6 & RCP 8.5 \\
\hline CNRM-CM5 & 138,133 & 182,436 & 21 & 27 & 130,518 & 225,491 & 20 & 34 \\
\hline GFDL-CM3 & 215,971 & 256,429 & 33 & 39 & 233,127 & 319,962 & 35 & 48 \\
\hline HadGEM2-ES & 174,295 & 246,351 & 26 & 37 & 177,415 & 346,135 & 27 & 52 \\
\hline
\end{tabular}

\subsection{Climates and Climate Change in the Protected Areas}

The bioclimatic zones and strata were overlain on a map of the protected areas. All nine zones and 37 out of 41 bioclimatic strata are found in PAs. However, representation of the zones (Table 4) and strata (Supplementary Material Table S6) varied greatly. Of the whole area protected, $47 \%\left(19,513 \mathrm{~km}^{2}\right)$ is in the Hot and Mesic zone, $30 \%\left(12,564 \mathrm{~km}^{2}\right)$ in the Warm Temperate and Moist zone, and $11 \%$ $\left(4555 \mathrm{~km}^{2}\right)$ in the Extremely Hot and Moist zone (Table 4$)$. All other zones contributed $<5 \%$ each. The five coolest zones had $>30 \%$ of their total area protected, while the two driest zones had $<1 \%$.

Table 4. Representation of bioclimatic zones within protected areas in Myanmar.

\begin{tabular}{lrrrr}
\hline Bioclimatic Zone & $\begin{array}{r}\text { Total Area } \\
(\mathbf{k m})\end{array}$ & $\begin{array}{r}\text { Area Protected } \\
\left(\mathbf{k m}^{\mathbf{2}}\right)\end{array}$ & $\begin{array}{r}\text { \% of Zone } \\
\text { Protected }\end{array}$ & $\begin{array}{r}\text { \% of Total } \\
\text { Protected Area }\end{array}$ \\
\hline Extremely Cold and Wet & 3 & 1 & 33 & 0 \\
Extremely Cold and Mesic & 816 & 582 & 71 & 1 \\
Cold and Mesic & 2900 & 1958 & 68 & 5 \\
Cool Temperate and Moist & 4831 & 1529 & 32 & 4 \\
Warm Temperate and Mesic & 55,576 & 12,564 & 23 & 30 \\
Hot and Mesic & 219,324 & 19,513 & 9 & 47 \\
Hot and Dry & 78,900 & 326 & 0 & 1 \\
Extremely Hot and Moist & 224,377 & 4555 & 2 & 11 \\
Extremely Hot and Xeric & 77,215 & 646 & 1 & 2 \\
\hline
\end{tabular}


Projected changes in climate within the protected areas are similar to those for Myanmar as a whole, with most zones shifting upslope (Supplementary Material Table S7). By 2050, 64-70\% of all protected areas are projected to shift at least partly to different bioclimatic zones under RCP2.6 and $67-75 \%$ under RCP8.5, while $81-82 \%$ are projected to shift at least partly to new strata under RCP2.6 and 80-82\% under RCP8.5 (Supplementary Material Table S9). In most cases, the majority of each protected area remains in the same zone, but $0-5 \%$ of all protected areas are predicted to shift completely to different zones under RCP2.6 and $2-12 \%$ under RCP8.5, and $10-19 \%$ are predicted to shift completely to different strata under RCP2.6 and 17-26\% under RCP8.5 (Supplementary Material Table S10). The projected changes are similar but larger by 2070 (Supplementary Material Tables S8, S11 and S12). Several new strata are also projected to appear within the Cold and Mesic, Hot and Dry, Extremely Hot and Moist, and Extremely Hot and Xeric zones under both RCPs by 2050 and 2070 (Supplementary Material Tables S13 and S14). In the protected area system as a whole, under both RCPs, there are large declines in the areas of the four coolest zones and large increases in the areas of the two hottest zones by 2050 (Supplementary Material Table S7), but with the amount of change depending on the model. These changes are generally projected to increase further by 2070 (Supplementary Material Table S8). The spread among individual reserves is very broad: $0-100 \%$ of each PA shifting to a new zone and/or stratum (Supplementary Material Tables S15-S18). Both the smallest and largest percentage changes are in PAs with a small elevational range and/or total area, where the entire reserve either switches or does not.

\section{Discussion}

The bioclimatic stratification of Myanmar highlights the climatic diversity in the country, from the Extremely Cold and Mesic zone, above the alpine treeline on the tallest mountains in the north of the country, to the Extremely Hot and Moist zone, until recently largely occupied by tropical lowland rainforest, in the south, and the Extremely Hot and Xeric zone, with remnant patches of savanna and deciduous forests, in the center of the country. Representation of the bioclimatic zones and strata in protected areas is currently very uneven, with $>30 \%$ of the areas of four coolest zones being protected and $<1 \%$ of the two driest. To a large extent this reflects human pressures within these zones, with the cool high mountains sparsely populated, while the drier areas have had dense populations for centuries. The hyperdiverse Extremely Hot and Moist zone in the south is also underrepresented in terms of percentage area $(2 \%)$ and is now under threat from expanding plantations [25]. The percentage of the total land area protected in Myanmar $(<6 \%)$ is also small, by both regional and global standards, and well below both the $17 \%$ area target (Aichi target 11) agreed by the Convention on Biological Diversity for 2020 and the proposed 30\% area target for 2030 [41].

The three earth system models used in this study all project an acceleration of recent warming trends across the whole of Myanmar, but with a fairly large spread $\left(<1.5^{\circ} \mathrm{C}\right)$ among models in the amount of warming. This spread is even wider for rainfall, in terms of both the amount and the spatial pattern of increase and decreases. In most projections and over most of Myanmar, rainfall is projected to increase, but the projected increases are small relative to both current interannual variation and variability over the last 200 years [40]. Changes in the bioclimatic stratification are therefore dominated by the increases in temperature, resulting in an upwards shift in average elevation for all zones and strata. The hottest zones increase in area while the cooler zones decline, with the coldest disappearing with two models. Changes in the strata are greater, reflecting their narrower bounds, but mostly model-dependent. Up to a third of Myanmar's land area will change bioclimatic zone by 2070 , depending on the model and RCP, while up to half will change stratum. Projected changes within the protected area system are similar to those in the country as a whole, but individual reserves are highly variable, with a complete switch of bioclimatic zone or stratum in some small reserves, as well as some larger ones with a low elevational range.

The consequences of these climatic changes for biodiversity depend on how effective the bioclimatic stratification is as a proxy for species and ecosystems, both now and in the future. Too little biodiversity 
data is available in Myanmar to validate this assumption for the present day, but there is support from studies in similar ecosystems in southwest China [31] and the transboundary Kailash Sacred Landscape of China, India, and Nepal [42], as well as studies in other parts of the world. Validation of future predictions is not possible, but theory, paleoecological evidence, and some observations of responses to recent climate change suggests that the populations of many well-dispersed species will track changes in climate across the landscape $[14,15]$. However, poorly dispersed species and those with long life-cycles will not be able to keep up. In particular, most of the individual trees that will dominate Myanmar's forests in 2050 and 2070 are already growing and cannot move, although a majority of 20 tree species studied in Natma Taung National Park had a higher proportion of juveniles at the upper end of their ranges, suggesting that their populations will eventually shift upslope [43]. Failure to track rapid climate change creates ecosystems that are not in equilibrium with the climate of the time, with consequences that are currently unclear, but are likely to be include slower growth and increased vulnerability to pests and diseases [14].

An additional complication comes from the increase in carbon dioxide concentrations, which is not only the largest single driver of climate change, but also has a direct impact on plant physiology and thus on plant growth, competition, and vegetation [44]. This means that bioclimate alone cannot predict future vegetation structure and species composition, which will also depend on the $\mathrm{CO}_{2}$ concentration. In other words, future analogues of modern climates are not necessarily ecologically equivalent. Rising atmospheric $\mathrm{CO}_{2}$ does not impact animals directly, but they will be impacted indirectly through changes in vegetation structure and composition. A recent modeling study which simulated the impacts of climate change on vegetation in South Asia (including Myanmar), with and without increasing $\mathrm{CO}_{2}$, found that simulations with increasing $\mathrm{CO}_{2}$ resulted in transitions from savanna into forest and deciduous forest into evergreen forest which did not occur in the absence of elevated $\mathrm{CO}_{2}$ [44]. The vegetation model used (aDGVM2) does not include nutrient limitation, so the impacts of elevated $\mathrm{CO}_{2}$ may be overestimated, but woody invasion of savannas in other parts of the world has been attributed, in part, to this mechanism [45].

The disappearance from Myanmar of the coldest bioclimatic zone, Extremely Cold and Wet, will have little direct impact on biodiversity, since this represents the summit zone of Mt Khakaborazi, which is barren rock and ice. In contrast, the large declines in the areas of the next three coolest zones, in both the country as a whole and the protected area system, will substantially reduce the area available for species adapted to high-mountain forest and alpine habitats in Myanmar. Upward shifts of several hundreds meters in steep topography, where they represent horizontal movements of a kilometer or two, may be within the dispersal capacities of most plant and animal species, but the area available declines with altitude on most mountains, and reaches zero at the summit. On isolated high mountains, such as Mt Victoria (Natma Taung) (3074 m) in southwest Myanmar, endemic species found only near the summit face potential mountain-top extinction. At the other extreme, species occurring in protected areas with little or no elevational range, because of flat topography (such as Chatthin and Shwesettaw Wildlife Sanctuaries) or small size (such as Chungponkan Wildlife Sanctuary, Lawkanada Sanctuary, and Wetthikan Bird Sanctuary), are threatened by the total loss of the bioclimatic zones or strata to which they are adapted, as the entire protected area undergoes a shift. Species adapted to open forests and savanna, such as the endangered Eld's deer (Rucervus eldi thamin) may be particularly vulnerable to woody encroachment and canopy closure, as a result of climate change and/or rising atmospheric $\mathrm{CO}_{2}$ (see above).

The use of climatic data as a surrogate for biodiversity is not ideal, since bioclimatic zones and strata are not, in themselves, targets for conservation. This approach was necessitated by the patchy availability of biodiversity data in Myanmar. As more such data becomes available, it should be possible to calibrate the bioclimatic stratification in a way that makes it more useful for conservation planning [46]. Where biodiversity data is lacking, the addition of geological information would be an improvement on using just climate as a surrogate. Myanmar's extensive karsts, for example, support numerous narrow-range endemic species whose presence could not be predicted from climate alone. 
It would be possible to make recommendations for additional protected areas and the expansion of existing ones based on this study, although recommendations based on climate variables alone should only be a first step. The vulnerability of the existing protected areas depends not only on their exposure to climate change, as assessed here, but also on their resilience (indicated by size, isolation, topographic variability, etc.) and capacity for adaptation [47]. Clearly, both the total area and the representativeness of the protected area system need to be increased, and connectivity across climatic gradients should be enhanced to permit species movements [11]. Extensive restoration of degraded vegetation, both passively (by removing the causes of degradation) and actively (by planting), may be needed, particularly in some lowland and drier areas [48]. Reintroduction of locally extirpated animal species may be practical where hunting can be controlled.

However, the protected area system in Myanmar is not currently limited by technical knowledge, but rather reflects, to a large extent, the legacies of decades of armed internal conflicts, some of which continue at a lower level, despite cease fires and peace agreements. These conflicts have limited the collection of biodiversity data and continue to make it very difficult to create new protected areas agreed by both the central and regional governments. As in many other countries, biodiversity protection in Myanmar is intimately linked with a variety of political, social, and economic issues, and progress in conservation will depend on progress in solving all these. Experience in some of these countries suggests that the best way forward is to take the technical knowledge-in this case, from climate change science-as a starting point and then to focus on policy, planning, and management issues in dialogue with major stakeholders [49].

Finally, we focus in this paper on protected areas, but the same climatic changes will also impact agricultural and urban areas, both directly and through their impacts on the supply of water and other services from natural ecosystems. Biodiversity conservation is easier in remote, unpopulated, areas, but arguably most important near to where most people live. Natural and restored ecosystems can not only provide a reliable source of water, but also reduce the risk from floods, cyclones, and other extreme weather events, regulate local climates, and provide accessible recreational and tourism opportunities, and associated economic benefits for local people [50].

\section{Conclusions}

Myanmar's current protected area system is small for such a biodiversity-rich country and not representative of the country's great climatic diversity. Projected climate change will result in a general upward shift in climate zones to higher altitudes, as well as model-dependent changes in rainfall, which are mostly small compared with current variability. Threats to biodiversity are expected for mountain-top endemics on isolated peaks, for the biotas of small protected areas and those with a low elevational range, and, in combination with rising $\mathrm{CO}_{2}$ levels, to species dependent on open habitats vulnerable to woody encroachment. Biodiversity data are needed to refine predictions based on climate alone, but the major factors currently limiting the needed extensions to the protected area system are social and political, not scientific.

Supplementary Materials: The following are available online at http://www.mdpi.com/2225-1154/8/9/99/s1, Table S1: Projected changes in mean annual temperature and precipitation for Myanmar between 1960-2000 and 2050 and 2070, Table S2: Projected change in areal extent and mean elevation of bioclimatic zones and their upward shift by 2050, Table S3: Projected change in areal extent and mean elevation of bioclimatic zones and their upward shift by 2070, Table S4: Projected change in areal extent and mean elevation of bioclimatic strata and their upward shift by 2050, Table S5: Projected change in areal extent and mean elevation of bioclimatic strata and their upward shift by 2070, Table S6: Representation of bioclimatic strata within protected areas, Table S7: Projected change in areal extent and mean elevation of bioclimatic zones in protected areas and their upward shifts by 2050, Table S8: Projected change in areal extent and mean elevation of bioclimatic zones in protected areas and their upward shifts by 2070, Table S9: Percentage of all protected areas shifting to a different zone by 2050, Table S10: Percentage of all protected areas shifting to different strata by 2050, Table S11: Percentage of all protected areas shifting to a different zone by 2070, Table S12: Percentage of all protected areas shifting to different strata by 2070, Table S13; Projected change in areal extent and mean elevation of bioclimatic strata in protected areas and their upward shifts by 2050, Table S14. Projected change in areal extent and mean elevation of bioclimatic strata in protected areas and their upward shifts by 2070, Table S15: Percentage shift of each protected area to different 
bioclimatic zone for 2050 and 2070, Table S16: Percentage shift of each protected area to different bioclimatic strata for 2050 and 2070, Table S17: Projected change in areal extent of bioclimatic zones in each protected area by 2050, Table S18: Projected change in areal extent of bioclimatic zones in each protected area by 2070, Figure S1: Change in mean annual temperature as projected for the year 2050, Figure S2: Change in mean annual temperature as projected for the year 2070, Figure S3: Change in maximum temperature of the warmest month as projected for the year 2050, Figure S4: Change in maximum temperature of the warmest month as projected for the year 2070, Figure S5: Change in mean annual precipitation as projected for the year 2050, Figure S6: Change in mean annual precipitation as projected for the year 2070, Figure S7: Bioclimatic stratification of Myanmar based on spatially interpolated weather station data and as projected for 2050, Figure S8: Bioclimatic stratification of Myanmar based on spatially interpolated weather station data and as projected for 2070.

Author Contributions: Conceptualization, T.N. and R.T.C.; methodology, T.N., R.J.Z., and R.T.C.; formal analysis, T.N. R.J.Z., and R.T.C.; writing-original draft preparation, T.N. and R.T.C.; writing-review, editing, and revision, all authors; supervision, R.T.C. All authors have read and agreed to the published version of the manuscript.

Funding: This research was funded by the Global Environment Facility grant GEF-5810 'Spatial Planning for Area Conservation in Response to Climate Change (SPARC)'.

Acknowledgments: We want to acknowledge: at XTBG, Alice Hughes, for her crucial help with the spatial modeling, Nirunrut Pomoim, for advice and assistance, and Lin Li for logistic and practical support; at Conservation International, Patrick Roehrdanz, for data, advice, and support; and in Myanmar, Shwe Yi Phoo Phoo (Range Officer, Watershed Management Division, Forest Department) and Thazin Htay (Range Officer, Planning and Statistics Division, Forest Department) for their suggestions and help, and the Forest Department, Ministry of Natural Resources and Environmental Conservation, for providing protected area shapefiles and other data. Three anonymous reviewers provided useful suggestions for the revision of the original submission.

Conflicts of Interest: The authors declare no conflict of interest. The funders had no role in the design of the study; in the collection, analyses, or interpretation of data; in the writing of the manuscript, or in the decision to publish the results.

\section{References}

1. Corlett, R.T. The Ecology of Tropical East Asia, 3rd ed.; Oxford University Press: Oxford, UK, 2019.

2. Hughes, A.C. Understanding the drivers of Southeast Asian biodiversity loss. Ecosphere 2017, 8, e01624. [CrossRef]

3. Rosa, I.M.D.; Smith, M.J.; Wearn, O.R.; Purves, D.; Ewers, R.M. The environmental legacy of modern tropical deforestation. Curr. Biol. 2016, 26, 2161-2166. [CrossRef] [PubMed]

4. Tilker, A.; Abrams, J.F.; Mohamed, A.; Nguyen, A.; Wong, S.T.; Sollmann, R.; Niedballa, J.; Bhagwat, T.; Gray, T.N.E.; Rawson, B.M.; et al. Habitat degradation and indiscriminate hunting differentially impact faunal communities in the Southeast Asian tropical biodiversity hotspot. Commun. Biol. 2019, 2, 296. [CrossRef] [PubMed]

5. Gray, T.N.E.; Hughes, A.C.; Laurance, W.F.; Long, B.; Lynam, A.J.; O’Kelly, H.; Ripple, W.J.; Seng, T.; Scotson, L.; Wilkinson, N.M. The wildlife snaring crisis: An insidious and pervasive threat to biodiversity in Southeast Asia. Biodivers. Conserv. 2018, 27, 1031-1037. [CrossRef]

6. McEvoy, J.F.; Connette, G.; Huang, Q.; Soe, P.; Pyone, K.H.H.; Valitutto, M.; Htun, Y.L.; Lin, A.N.; Thant, A.L.; Htun, W.Y.; et al. Two sides of the same coin-Wildmeat consumption and illegal wildlife trade at the crossroads of Asia. Biol. Conserv. 2019, 238, 108197. [CrossRef]

7. Arfanuzzaman, M.; Dahiya, B. Sustainable urbanization in Southeast Asia and beyond: Challenges of population growth, land use change, and environmental health. Growth Chang. 2019, 50, 725-744. [CrossRef]

8. Hijioka, Y.; Lin, E.; Pereira, P.P.; Corlett, R.T.; Cui, X.; Insarov, G.E.; Lasco, R.D.; Lindgren, E.; Surjan, A. Asia. In Climate Change 2014: Impacts, Adaptation, and Vulnerability. Part B: Regional Aspects; Cambridge University Press: Cambridge, UK, 2017; pp. 1327-1370.

9. Hawkins, E.; Frame, D.; Harrington, L.; Joshi, M.; King, A.; Rojas, M.; Sutton, R. Observed emergence of the climate change signal: From the familiar to the unknown. Geophys. Res. Lett. 2020, 47, e2019GL086259. [CrossRef]

10. Lehikoinen, P.; Lehikoinen, A.; Santangel, A.; Jaatinen, K.; Rajasärkkä, A. Protected areas act as a buffer against detrimental effects of climate change-Evidence from large-scale, long-term abundance data. Glob. Change Biol. 2019, 25, 304-313. [CrossRef]

11. Hoffmann, S.; Irl, S.D.H.; Beierkuhnlein, C. Predicted climate shifts within terrestrial protected areas worldwide. Nat. Commun. 2019, 10, 4787. [CrossRef] 
12. Årevall, J.; Early, R.; Estrada, A.; Wennergren, U.; Eklöf, A.C. Conditions for successful range shifts under climate change: The role of species dispersal and landscape configuration. Divers. Distrib. 2018, 24, 1598-1611. [CrossRef]

13. Corlett, R.T.; Tomlinson, K.W. Climate change and edaphic specialists: Irresistible force meets immovable object? Trends Ecol. Evol. 2020, 35, 367-376. [CrossRef] [PubMed]

14. Corlett, R.T.; Westcott, D.A. Will plant movements keep up with climate change? Trends Ecol. Evol. 2013, 28, 482-488. [CrossRef] [PubMed]

15. Brito-Morales, I.; García Molinos, J.; Schoeman, D.S.; Burrows, M.T.; Poloczanska, E.S.; Brown, C.J.; Ferrier, S.; Harwood, T.D.; Klein, C.J.; McDonald-Madden, E.; et al. Climate velocity can inform conservation in a warming world. Trends Ecol. Evol. 2018, 33, 441-457. [CrossRef] [PubMed]

16. Monzón, J.; Moyer-Horner, L.; Palamar, M.B. Climate change and species range dynamics in protected areas. Bioscience 2011, 61, 752-761. [CrossRef]

17. Hannah, L.; Roehrdanz, P.R.; Marquet, P.A.; Enquist, B.J.; Midgley, G.; Foden, W.; Lovett, J.C.; Corlett, R.T.; Corcoran, D.; Butchart, S.H.M.; et al. 30\% land conservation and climate action reduces tropical extinction risk by more than 50\%. Ecography 2020, 43, 943-953. [CrossRef]

18. Horton, R.; De Mel, M.; Peters, D.; Lesk, C.; Bartlett, R.; Helsingen, H.; Bader, D.; Capizzi, P.; Martin, S.; Rosenzweig, C. Assessing Climate Risk in Myanmar: Technical Report; Center for Climate Systems Research at Columbia University, WWF-US and WWF-Myanmar: New York, NY, USA, 2017.

19. Forest Department. National Biodiversity Strategy and Action Plan (2015-2020); Ministry of Environmental Conservation and Forestry: Naypyidaw, Myanmar, 2015.

20. FAO. Global Forest Resources Assessment 2020: Main Report; Food and Agriculture Organization of the United Nations: Rome, Italy, 2020.

21. De Alban, J.D.T.; Jamaludin, J.; Wong, D.d.W.; Than, M.M.; Webb, E.L. Improved estimates of mangrove cover and change reveal catastrophic deforestation in Myanmar. Environ. Res. Lett. 2020, 15, 034034. [CrossRef]

22. Macdonald, D.W.; Bothwell, H.M.; Kaszta, Ż.; Ash, E.; Bolongon, G.; Burnham, D.; Can, Ö.E.; Campos-Arceiz, A.; Channa, P.; Clements, G.R.; et al. Multi-scale habitat modelling identifies spatial conservation priorities for mainland clouded leopards (Neofelis nebulosa). Divers. Distrib. 2019, 25, 1639-1654. [CrossRef]

23. Zhang, Y.; Prescott, G.W.; Tay, R.E.; Dickens, B.L.; Webb, E.L.; Htun, S.; Tizard, R.J.; Rao, M.; Carrasco, L.R. Dramatic cropland expansion in Myanmar following political reforms threatens biodiversity. Sci. Rep. 2018, 8, 1-10. [CrossRef]

24. Michinaka, T.; Hlaing, E.E.S.; Oo, T.N.; Mon, M.S.; Sato, T. Forecasting forest areas in Myanmar based on socioeconomic factors. Forests 2020, 11, 100. [CrossRef]

25. Zaehringer, J.G.; Lundsgaard-Hansen, L.; Thein, T.T.; Llopis, J.C.; Tun, N.N.; Myint, W.; Schneider, F. The cash crop boom in southern Myanmar: Tracing land use regime shifts through participatory mapping. Ecosyst. People 2020, 16, 36-49. [CrossRef]

26. Rao, M.; Htun, S.; Platt, S.G.; Tizard, R.; Poole, C.; Myint, T.; Watson, J.E.M. Biodiversity conservation in a changing climate: A review of threats and implications for conservation planning in Myanmar. Ambio 2013, 42, 789-804. [CrossRef] [PubMed]

27. Eckstein, D.; Künzel, V.; Schäfer, L.; Winges, M. Global Climate Risk Index 2020; GermanWatch: Bonn, Germany, 2020.

28. MONREC. Myanmar Climate Change Master Plan (2018-2030); Ministry of Natural Resources and Environmental Conservation: Naypyidaw, Myanmar, 2019.

29. Kimengsi, J.N.; Aung, P.S.; Pretzsch, J.; Haller, T.; Auch, E. Constitutionality and the co-management of protected areas: Reflections from Cameroon and Myanmar. Int. J. Commons 2019, 13, 1003-1020. [CrossRef]

30. Ministry of Natural Resources and Environmental Conservation, Forest Department. Available online: https://www.forestdepartment.gov.mm/ (accessed on 22 May 2020).

31. Zomer, R.J.; Xu, J.; Wang, M.; Trabucco, A.; Li, Z. Projected impact of climate change on the effectiveness of the existing protected area network for biodiversity conservation within Yunnan Province, China. Biol. Conserv. 2015, 184, 335-345. [CrossRef]

32. Soteriades, A.D.; Murray-Rust, D.; Trabucco, A.; Metzger, M.J. Understanding global climate change scenarios through bioclimate stratification. Environ. Res. Lett. 2017, 12, 084002. [CrossRef] 
33. Metzger, M.J.; Bunce, R.G.H.; Jongman, R.H.G.; Sayre, R.; Trabucco, A.; Zomer, R. A high-resolution bioclimate map of the world: A unifying framework for global biodiversity research and monitoring. Glob. Ecol. Biogeogr. 2013, 22, 630-638. [CrossRef]

34. Hijmans, R.J.; Cameron, S.E.; Parra, J.L.; Jones, P.G.; Jarvis, A. Very high resolution interpolated climate surfaces for global land areas. Int. J. Climatol. 2005, 25, 1965-1978. [CrossRef]

35. Zomer, R.J.; Trabucco, A.; Bossio, D.A.; Verchot, L.V. Climate change mitigation: A spatial analysis of global land suitability for clean development mechanism afforestation and reforestation. Agric. Ecosyst. Environ. 2008, 126, 67-80. [CrossRef]

36. Hargreaves, G.H. Defining and using reference evapotranspiration. J. Irrig. Drain. E-ASCE 1994, 120, 1132-1139. [CrossRef]

37. McSweeney, C.F.; Jones, R.G.; Lee, R.W.; Rowell, D.P. Selecting CMIP5 GCMs for downscaling over multiple regions. Clim. Dyn. 2015, 44, 3237-3260. [CrossRef]

38. Kamworapan, S.; Surussavadee, C. Evaluation of CMIP5 global climate models for simulating climatological temperature and precipitation for Southeast Asia. Adv. Meteorol. 2019, 2019, 1067365. [CrossRef]

39. van Vuuren, D.P.; Edmonds, J.; Kainuma, M.; Riahi, K.; Thomson, A.; Hibbard, K.; Hurtt, G.C.; Kram, T.; Krey, V.; Lamarque, J.F.; et al. The representative concentration pathways: An overview. Clim. Chang. 2011, 109, 5. [CrossRef]

40. Zaw, Z.; Fan, Z.-X.; Bräuning, A.; Xu, C.-X.; Liu, W.-J.; Gaire, N.P.; Panthi, S.; Tha, K.Z. Drought reconstruction over the past two centuries in southern Myanmar using teak tree-rings: Linkages to the Pacific and Indian Oceans. Geophys. Res. Lett. 2020, 47, e2020GL087627. [CrossRef]

41. CBD. Zero Draft of the Post-2020 Global Biodiversity Framework; Convention on Biological Diversity: Montreal, QC, Canada, 2020.

42. Zomer, R.J.; Trabucco, A.; Metzger, M.J.; Wang, M.; Oli, K.P.; Xu, J. Projected climate change impacts on spatial distribution of bioclimatic zones and ecoregions within the Kailash Sacred Landscape of China, India, Nepal. Clim. Chang. 2014, 125, 445-460. [CrossRef]

43. Thang, T.M.; Thu, A.M.; Chen, J. Tree species of tropical and temperate lineages in a tropical Asian montane forest show different range dynamics in response to climate change. Glob. Ecol. Conserv. 2020, 22, e00973. [CrossRef]

44. Kumar, D.; Pfeiffer, M.; Gaillard, C.; Langan, L.; Scheiter, S. Climate change and elevated $\mathrm{CO}_{2}$ favor forest over savanna under different future scenarios in South Asia. Biogeosci. Discuss. 2020. [CrossRef]

45. Stevens, N.; Erasmus, B.F.; Archibald, S.; Bond, W.J. Woody encroachment over 70 years in South African savannahs: Overgrazing, global change or extinction aftershock? Philos. Trans. R. Soc. Lond. B Biol. Sci. 2016, 371, 20150437. [CrossRef]

46. Beier, P.; Sutcliffe, P.; Hjort, J.; Faith, D.P.; Pressey, R.L.; Albuquerque, F. A review of selection-based tests of abiotic surrogates for species representation. Conserv. Biol. 2015, 29, 668-679. [CrossRef]

47. Lapola, D.M.; da Silva, J.M.; Braga, D.R.; Carpigiani, L.; Ogawa, F.; Torres, R.R.; Barbosa, L.C.F.; Ometto, J.P.H.B.; Joly, C.A. A climate-change vulnerability and adaptation assessment for Brazil's protected areas. Conserv. Biol. 2019, 34, 427-437. [CrossRef]

48. Bustamente, M.M.C. Ecological restoration as a strategy for mitigating and adapting to climate change: Lessons and challenges from Brazil. Mitig. Adapt. Strateg. Glob. Chang. 2019, 24, 1249-1270. [CrossRef]

49. van Kerkhoff, L.; Munera, C.; Dudley, N.; Guevara, O.; Wyborn, C.; Figueroa, C.; Dunlop, M.; Hoyos, M.A.; Castiblanco, J.; Becerra, L. Towards future-oriented conservation: Managing protected areas in an era of climate change. Ambio 2019, 48, 699-713. [CrossRef]

50. Corlett, R.T. Safeguarding our future by protecting biodiversity. Plant Divers. 2020. [CrossRef] [PubMed]

(C) 2020 by the authors. Licensee MDPI, Basel, Switzerland. This article is an open access article distributed under the terms and conditions of the Creative Commons Attribution (CC BY) license (http://creativecommons.org/licenses/by/4.0/). 